\title{
Reliability of diagnosis and clinical efficacy of visceral osteopathy: a systematic review
}

Albin Guillaud ${ }^{1,2,4}$, Nelly Darbois ${ }^{1,4}$, Richard Monvoisin ${ }^{1,4}$ and Nicolas Pinsault ${ }^{2,3,4^{*}}$ (D)

\begin{abstract}
Background: In 2010, the World Health Organization published benchmarks for training in osteopathy in which osteopathic visceral techniques are included. The purpose of this study was to identify and critically appraise the scientific literature concerning the reliability of diagnosis and the clinical efficacy of techniques used in visceral osteopathy.

Methods: Databases MEDLINE, OSTMED.DR, the Cochrane Library, Osteopathic Research Web, Google Scholar, Journal of American Osteopathic Association (JAOA) website, International Journal of Osteopathic Medicine (IJOM) website, and the catalog of Académie d'ostéopathie de France website were searched through December 2017. Only inter-rater reliability studies including at least two raters or the intra-rater reliability studies including at least two assessments by the same rater were included. For efficacy studies, only randomized-controlled-trials (RCT) or crossover studies on unhealthy subjects (any condition, duration and outcome) were included. Risk of bias was determined using a modified version of the quality appraisal tool for studies of diagnostic reliability (QAREL) in reliability studies. For the efficacy studies, the Cochrane risk of bias tool was used to assess their methodological design. Two authors performed data extraction and analysis.

Results: Eight reliability studies and six efficacy studies were included. The analysis of reliability studies shows that the diagnostic techniques used in visceral osteopathy are unreliable. Regarding efficacy studies, the least biased study shows no significant difference for the main outcome. The main risks of bias found in the included studies were due to the absence of blinding of the examiners, an unsuitable statistical method or an absence of primary study outcome.
\end{abstract}

Conclusions: The results of the systematic review lead us to conclude that well-conducted and sound evidence on the reliability and the efficacy of techniques in visceral osteopathy is absent.

Trial registration: The review is registered PROSPERO 12th of December 2016. Registration number is CRD4201605286.

\section{Background}

The practice of osteopathy was founded in 1874 by Andrew Taylor Still in the USA [1]. For the World Health Organization (WHO), osteopathy is a complementary and alternative medicine consisting of manual techniques for diagnosis and treatment for diverse conditions (such as musculoskeletal and gastrointestinal complaints) [2]. Reliable empirical data concerning different types of techniques used in osteopathic practice are rare, essentially due to the poor representativeness of the

\footnotetext{
* Correspondence: npinsault@chu-grenoble.fr

${ }^{2}$ ThEMAS team, TIMC-IMAG laboratory, UMR CNRS-UGA, 5525 Grenoble, France

${ }^{3}$ School of Physiotherapy, Grenoble-Alpes University Hospital, Paris, France Full list of author information is available at the end of the article
}

samples studied. Among all patients treated by osteopaths, the number receiving visceral osteopathy varies widely, from $1 \%$ to $95 \%[3,4]$. Despite the fact that teaching of visceral osteopathy has been banned in some countries (e.g., France [5]), the WHO incorporated visceral techniques in its benchmarks for training in osteopathy in 2010 [2]. However, the introduction of a discipline into clinical benchmarks and more generally into health care systems should require rigorous proofs of safety, efficacy and quality assurance. To fulfill this standard, the patient diagnostic techniques and the therapies themselves must be shown to be both reliable and effective.

From a historical point of view, the concept of visceral osteopathy was introduced by the French osteopath 
Jacques Weischenck in the 1980s [6]. The subsequent 1983 publication by the French osteopaths Jean-Pierre Barral and Pierre Mercier [7] is relied upon by most osteopaths.

According to the theory proposed by its founders, visceral osteopathy is essentially described in mechanical terms and focuses on the intra-abdominal organs [6, 7]. Starting from the observation that intra-abdominal viscera naturally move (for example due to breathing), it is argued that this mobility could be disturbed in the same way that articular mobility can be disturbed [7]. From a physiopathological point of view, it is claimed that these disturbances can trigger, increase or maintain musculoskeletal (e.g., low back pain) or gastrointestinal complaints (e.g., irritable bowel disorders) [6, 7], among others. Consequently, visceral osteopaths propose that these mobility disturbances can be detected by palpation and treated by manipulation [6,7]. Currently, none of the theoretical aspects of visceral osteopathy have received serious empirical support apart from the possibility of disturbance of viscera mobility [8]. Moreover, no systematic review has investigated the evidence of intraand inter-examiner reliability of the diagnostic techniques used in visceral osteopathy.

One literature review has been performed on the efficacy of therapeutic strategies in visceral osteopathy [9]. This review is unfortunately neither systematic (no research, inclusion, and analysis methods) nor specific to visceral osteopathy because it includes studies on abdominal massage. This paper proposes two systematic reviews to identify and critically appraise the scientific literature concerning 1) the reliability of the diagnostic techniques and 2) the clinical efficacy of techniques used in visceral osteopathy.

\section{Methods}

The protocol was registered on PROSPERO (CRD 42016052861: http://www.crd.york.ac.uk/PROSPERO/display_record.asp?ID=CRD42016052861) on 12 December 2016, and followed PRISMA (Preferred Reporting Items for Systematic Reviews and Meta-Analyses) recommendations http://prisma-statement.org.

\section{Data sources and searches}

In December 2017, the following literature sources were searched: MEDLINE, OSTMED.DR, the Cochrane Library, Osteopathic Research Web, Google Scholar, Journal of American Osteopathic Association (JAOA), International Journal of Osteopathic Medicine (IJOM) websites, and the catalog of Académie d'ostéopathie de France.

(See Additional file 1: Appendix 1, for search terms and equations).
The search was performed until the 21th of December 2017. No restrictions were applied concerning publication date or publication language.

For the sake of completeness, a complementary search was conducted. It consisted of analyzing the list of references of included articles, reading previous systematic reviews, and contacting professional organizations or the authors of unpublished studies for additional studies.

\section{Study selection}

Only inter-rater reliability studies including at least two raters or the intra-rater reliability studies including at least two assessments by the same rater were included. Furthermore, only studies on humans (healthy or unhealthy subjects) were retained. Concerning the interventions evaluated, all studies regarding techniques mentioned in the classical visceral osteopathic literature or claimed by authors to be in the field of visceral osteopathy were retained. The benefit of doubt was given to techniques of whose membership to visceral osteopathy could not be ascertained clearly.

For efficacy studies, only randomized-controlled-trials (RCT) or crossover studies on unhealthy subjects (any condition, duration and outcome) were included. Concerning the interventions evaluated, the same principle as for reliability studies was applied (see above). Other exclusion criteria were: non-comparative trials, noncrossover study, an absence of a clear mention of the use of visceral osteopathy techniques, and studies in which combined treatments were assessed (as in osteopathic manual therapy - OMT) without performing subgroup analysis, and eventually studies for which the full text version is unavailable. No restriction was made concerning the type of illness, the type of outcomes or the type of healthcare services.

Three stages composed the systematic selection process. Firstly, a selection was made based on the title of the article. Second, each abstract was evaluated. At this stage, studies that did not meet the eligibility criteria were excluded. Finally, full-text articles were read for a last application of the eligibility criteria. One author performed the systematic selection process. For the studies gathered through the complementary approach, their abstracts, or if needed, the full-text articles, were also analyzed.

\section{Data extraction and quality assessment}

Two authors performed the data extraction. The data extracted are: the design of the study (with randomization and blinding procedures), sample size and features (e.g., age and/or disease or inclusion criteria), as well as primary and secondary outcomes. Regarding reliability studies, additional information are presented concerning raters (such as number, qualification or expertise) as well as the statistical analysis carried out. As regards efficacy studies, 
a brief description of the techniques implemented is also presented.

In accordance with PRISMA recommendations http:// prisma-statement.org, risk of bias assessments were made independently by two reviewers with standard forms. In case that the risks of bias cannot be fully assessed due to missing information, the corresponding author of the publication (or failing that, the lead author) was contacted to obtain the information necessary to assess the risks of bias. All authors were contacted on the 20th of December 2017. The authors who did not respond were contacted again on the 28 th of December 2017.

Reviewers resolved disagreements through discussion and consensus. When no consensus could be reached, a third reviewer made the decision.

\section{Reliability studies}

As regards reliability studies, the risk of bias was assessed in each study using a modified version of the quality appraisal tool for studies of diagnostic reliability (QAREL) [10]. [Note: In comparison to our previous systematic review [10], we withdraw the item "rater's experience" because an end-study student may be better trained than a recently graduated practitioner. Moreover, it is always possible to carry out a subgroup statistical analysis to assess a potential expertise effect. It should be noted that the withdrawal of this item does not change the conclusion for our previous review on cranial osteopathy [10]]. The general assessment of risk of bias for a reliability study is: 'High risk of bias' if at least one item is assessed with a high risk of bias; 'Major doubt about risk of bias' if more than two items are assessed with an unclear risk of bias and with all other items with a low risk of bias; 'Minor doubt about risk of bias' if two or fewer items are assessed with an unclear risk of bias and with all others with a low risk of bias; and overall 'Low risk of bias' if all items are assessed with a low risk of bias [10].

In addition to the general assessment of risk of bias, the results of reliability studies are analyzed and interpreted. The reliability is considered to be satisfactory when the intraclass correlation coefficient (ICC) is above 0.75 , according to the Fleiss' classification, or when the kappa coefficient ( $\mathrm{k}$ ) is above 0.81 , according to the Landis \& Koch classification $[11,12]$. The targets set could be regarded as high for manual techniques. However, as visceral osteopathy is mainly founded on a causal hypothesis without evidence, these precautions were deemed to be required.

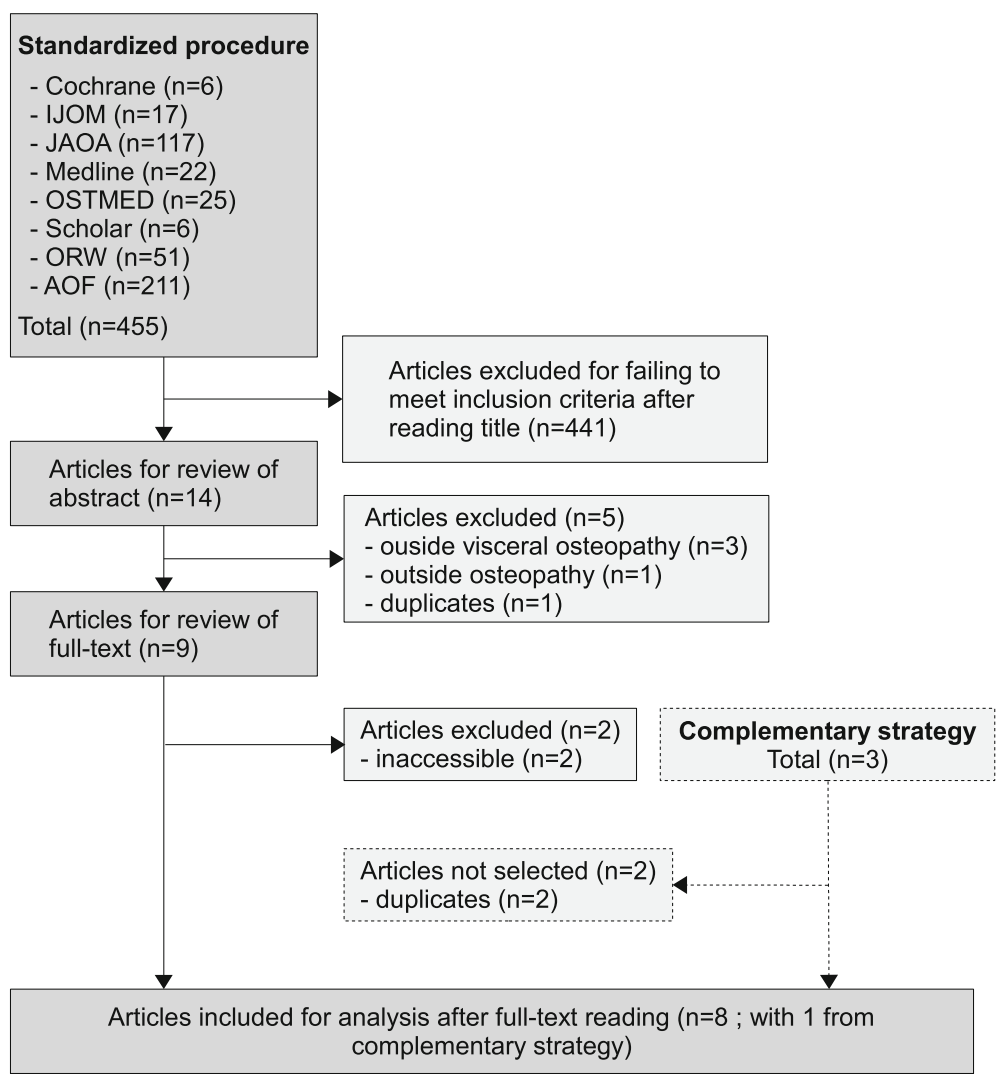

Fig. 1 Flow chart of the study selection process for the systematic review of studies dealing with the reliability of diagnosis in the field of visceral osteopathy 
Concerning statistical methods for reliability studies, according to Lucas et al. [13], it is considered that intraclass correlation coefficient, is appropriate for rating inter-rater reliability when the variables are quantitative, ordinal, interval, and ratio variables, while kappa coefficient is appropriate for nominal (i.e., categorical) variables. Other statistical measures of reliability exist, such as Spearman or Pearson correlations, percentage agreement or measures of precision (for example, confidence limits), but they are not adapted for measuring reliability $[13,14]$.

Table 1 Summary of included studies dealing with the reliability of diagnosis in visceral osteopathy

\begin{tabular}{|c|c|c|c|c|c|}
\hline First authors & $\begin{array}{l}\text { Subjects (number; disease } \\
\text { status; age in yrs) }\end{array}$ & $\begin{array}{l}\text { Raters (number; } \\
\text { degree(s); expertise) }\end{array}$ & $\begin{array}{l}\text { Study Characteristics \& } \\
\text { Parameter(s) }\end{array}$ & $\begin{array}{l}\text { Reliability } \\
\text { Measure } \\
\text { Used }\end{array}$ & $\begin{array}{l}\text { Main } \\
\text { Results }\end{array}$ \\
\hline $\begin{array}{l}\text { Landry } \\
{[16]}\end{array}$ & $\begin{array}{l}N=41 ; \text {, healthy; } \\
A=24\end{array}$ & $\begin{array}{l}N=2 ; \text { last-year } \\
\text { osteopathy students; } \\
\text { clinical internships. }\end{array}$ & $\begin{array}{l}\text { Inter-rater: (1) proximal- } \\
\text { duodenum-area mobility; (2) } \\
\text { distal-duodenum-area } \\
\text { mobility (4 possible } \\
\text { modalities for } \\
\text { (1) \& (2)). }\end{array}$ & $\begin{array}{l}\text { Cohens's } \\
\text { kappa }\end{array}$ & $\begin{array}{l}\text { Inter: (1): } 0.14 \text { (2): } \\
0.0448\end{array}$ \\
\hline $\begin{array}{l}\text { Terrier } \\
{[17]}\end{array}$ & $\begin{array}{l}N=50 ; \text { patients in } \\
\text { osteopathic cares; } \\
\mathrm{A}=33\end{array}$ & $\begin{array}{l}\mathrm{N}=2 \text {; last-year } \\
\text { osteopathy students; } \\
\text { clinical internships. }\end{array}$ & $\begin{array}{l}\text { Inter-rater: ascendant- } \\
\text { colon-area dynamic } \\
\text { (4 possible modalities). }\end{array}$ & $\begin{array}{l}\text { Cohens's } \\
\text { kappa }\end{array}$ & Inter: 0.322 \\
\hline $\begin{array}{l}\text { Rittler } \\
{[18]}\end{array}$ & $\begin{array}{l}N=18 \text {; osteopathy } \\
\text { students with an } \\
\text { "osteopathic } \\
\text { dysfunction"; } \\
\text { not reported. }\end{array}$ & $\begin{array}{l}N=6 \text {; osteopaths } \\
\text { graduated in 2009; } 5 \\
\text { use usually the } \\
\text { assessed test and } 1 \\
\text { has never used it. }\end{array}$ & $\begin{array}{l}\text { Intra \& inter-rater: posture } \\
\text { variations ("global listening } \\
\text { test"; } 6 \text { modalities). }\end{array}$ & $\begin{array}{l}\text { Cohens's } \\
\text { kappa }\end{array}$ & $\begin{array}{l}\text { Intra: from }-0.05 \\
\text { to } 0.12 \\
\text { Inter: from }-0.25 \\
\text { to } 0.37\end{array}$ \\
\hline $\begin{array}{l}\text { Gruber } \\
{[19]}\end{array}$ & $\begin{array}{l}N=43 ; 20 \text { healthy } \\
\text { and } 21 \text { spine-painful } \\
\text { patients; } A=30-75\end{array}$ & $\begin{array}{l}N=2 ; \text { osteopaths } \\
\text { graduated in 2009; } \\
6 \text { yrs. }\end{array}$ & $\begin{array}{l}\text { Intra \& inter-rater: } \\
\text { abdominal diaphragm } \\
\text { tension ( } 2 \text { modalities: } \\
\text { symmetrical or asymmetrical). }\end{array}$ & $\begin{array}{l}\text { Cohens's } \\
\text { kappa }\end{array}$ & $\begin{array}{l}\text { intra: from }-0.02 \\
\text { to } 0.57 \\
\text { inter: }-0.35\end{array}$ \\
\hline $\begin{array}{l}\text { Cònsol } \\
\text { Urgellés } \\
\text { [20] }\end{array}$ & $\begin{array}{l}N=40 ; \text { not } \\
\text { reported; } \\
\mathrm{A}=33\end{array}$ & $\begin{array}{l}\mathrm{N}=3 ; \text { osteopaths; } \\
\text { recently graduated. }\end{array}$ & $\begin{array}{l}\text { Intra \& inter-rater: (1) } \\
\text { radial pulse evolution } \\
\text { during the Adson-Wright } \\
\text { test (or Soto-Hall } \\
\text { test) ( } 3 \text { modalities: } \\
\text { presence, de } \\
\text { crease or abolition); } \\
\text { (2) When (1) is "decrease" } \\
\text { or "abolition", location of the } \\
\text { "visceral osteopathic dysfunction". }\end{array}$ & Fleiss'kappa & $\begin{array}{l}\text { Intra: (1) from } 0.65 \text { to } \\
1 ;(2) \text { from } 0.63 \text { to } 1 \\
\text { Inter: (1) from } 0.61 \\
\text { to } 0.70 ;(2) \text { from }-0.14 \\
\text { to } 0.61\end{array}$ \\
\hline $\begin{array}{l}\text { Zeller } \\
\text { [21] }\end{array}$ & $\begin{array}{l}N=44 ; 24 \text { patients with an } \\
\text { "asymptomatic hepatic } \\
\text { dysfunction" and } 20 \text { with a } \\
\text { symptomatic hepatic } \\
\text { issue ; } A=27-73 .\end{array}$ & $\begin{array}{l}\mathrm{N}=2 \text {; osteopath- } \\
\text { physiotherapists; } \\
2 \text { yrs. in osteopathy } \\
\text { and over } 10 \text { yrs. in } \\
\text { physiotherapy. }\end{array}$ & $\begin{array}{l}\text { Inter-rater: hepatic-area } \\
\text { mobility (4 modalities). }\end{array}$ & $\begin{array}{l}\text { Cohens's } \\
\text { kappa }\end{array}$ & Inter: 0.26 \\
\hline $\begin{array}{l}\text { Darty } \\
{[22]}\end{array}$ & $\begin{array}{l}N=10 ; \text { healthy; } \\
A=23\end{array}$ & $\begin{array}{l}N=12 ; 5 \text { osteopaths } \\
\text { and } 7 \text { last-year } \\
\text { osteopathy students; } \\
\text { not reported. }\end{array}$ & $\begin{array}{l}\text { Intra \& inter-rater: (1) } \\
\text { sensibility; (2) "wall } \\
\text { depressibility"; (3) "organ } \\
\text { depressibility"; (4) "organ } \\
\text { location" ((1),(2), (3), (4) for } \\
\text { stomach, caecum, sigmoid } \\
\text { and transverse colon; } 4 \\
\text { modalities for (1), (2), (3) } \\
\text { and distance measure for } \\
\text { (4)); (5) "organ volume" } \\
\text { (metrical measure; } \\
\text { not for stomach). }\end{array}$ & $\begin{array}{l}\text { Intra: } \\
\text { variation } \\
\text { coefficient } \\
\text { (VC) } \\
\text { Inter: } \\
\text { Student } \\
\text { test, correlation } \\
\text { coefficient } \\
\text { and ICC. }\end{array}$ & 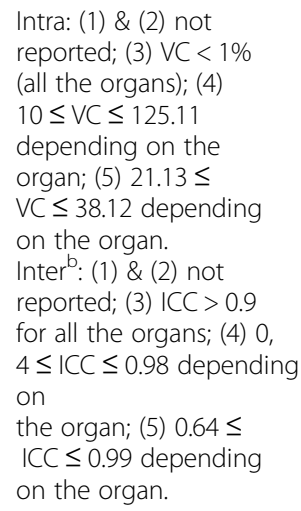 \\
\hline $\begin{array}{l}\text { Verbaarschot } \\
\text { [23] }\end{array}$ & $\begin{array}{l}N=31 ; \text { healthy; } \\
\mathrm{A}=17-69\end{array}$ & $\begin{array}{l}\mathrm{N}=2 ; \text { osteopaths; } \\
\text { specifically trained } \\
\text { for the study. }\end{array}$ & $\begin{array}{l}\text { Intra-rater of: visceral } \\
\text { tension (3 modalities: } \\
\text { normal, "hypertension" } \\
\text { or "hypotension"). }\end{array}$ & $\begin{array}{l}\text { Cohens's } \\
\text { kappa }\end{array}$ & $\begin{array}{l}\text { Intra: from } 0.372 \\
\text { to } 0.542\end{array}$ \\
\hline
\end{tabular}




\section{Efficacy studies}

For efficacy studies, the risk of bias was assessed by means of the Cochrane risk of bias tool [15]. Considering that a high risk of bias in the blinding domain is inevitable in the manual therapy field, the general risk of bias is [10]: 'High risk of bias' if at least one item in addition to of "blinding" is assessed with a high risk of bias; 'Major doubt of risk of bias' if two or more items are assessed with an unclear risk of bias and with all other domains (aside from blinding) being assessed with a low risk of bias; 'Minor doubt of risk of bias' if only one item is assessed with an unclear risk of bias, and with all others (aside from blinding) being assessed with a low risk of bias; and 'Low risk of bias' if all items other than blinding are assessed with a low risk of bias.

\section{Role of the funding source}

This systematic review was funded by the French national council of physiotherapists [Conseil national de l'ordre des masseurs-kinésithérapeutes français]. The French national council of physiotherapists had no role in study design; collection analysis, or interpretation of data; or writing of the report.

\section{Results}

\section{Reliability studies}

455 articles were identified after the standardized bibliographic search. Of these, eight reached the inclusion criteria (Fig 1). The complementary approach gave three additional articles but only one reaching the inclusion criteria. Features of these studies are available in Table 1. Articles excluded after examination of the full text are available in Additional file 2: Appendix 2 with their main reason for exclusion.

Critical evaluation led to conclude that one study demonstrated a minor doubt about risk of bias [23] and that all other reliability studies had a high risk of bias, especially owing to the absence of blinding of the raters (Figs. $2 \& 3$ ). [Note: For the reliability studies, five points are concerned by blinding. The first point is "the prior findings of the test under evaluation" [13]. The second point, which only concerns inter-rater reliability studies, is the possibility of communication between the two raters during the study [13]. The third point is the possibility of communication between the two raters when a subject is tested at the same time by both raters [10]. The fourth point is the "Knowledge of clinical information provides indirect knowledge of the presence or absence of the target disorder or variable of interest and may influence a rater's decision regarding the outcome of the test." [13]. For example, clinical history. The fifth point is the "additional cues that are not part of the test" [13], such as tattoos, surgical scars or voice accent.] Seven studies dealt with inter-rater reliability [16$22]$ and 5 with intra-rater reliability [18-20]. Among the inter-rater reliability studies, 3 addressed visceral mobility and all three showing unreliable results $[16,17,21]$ The other studies were designed to evaluate different outcomes such as postture variations [18], abdominal diaphragm tensions [19], the location of a "visceral osteopathic dysfunction" [20] or organ depressibility [22], with three failing to demonstrate reliability [18-20] and one with selective report [22]. The five studies dealing with intra-rater reliability focused on the same outcomes mentioned previously $[18-20,22]$ plus one study investigating "visceral tensions" [23]. They obtained similar results to the inter-rater reliability studies.

\section{Efficacy studies}

1413 articles were identified after the standard search procedure. Of these, six reached the inclusion criteria (Fig 4). In the complementary approach 4 additional articles were found with none meeting the inclusion criteria. Features of these six studies are available in Table 2. Articles excluded

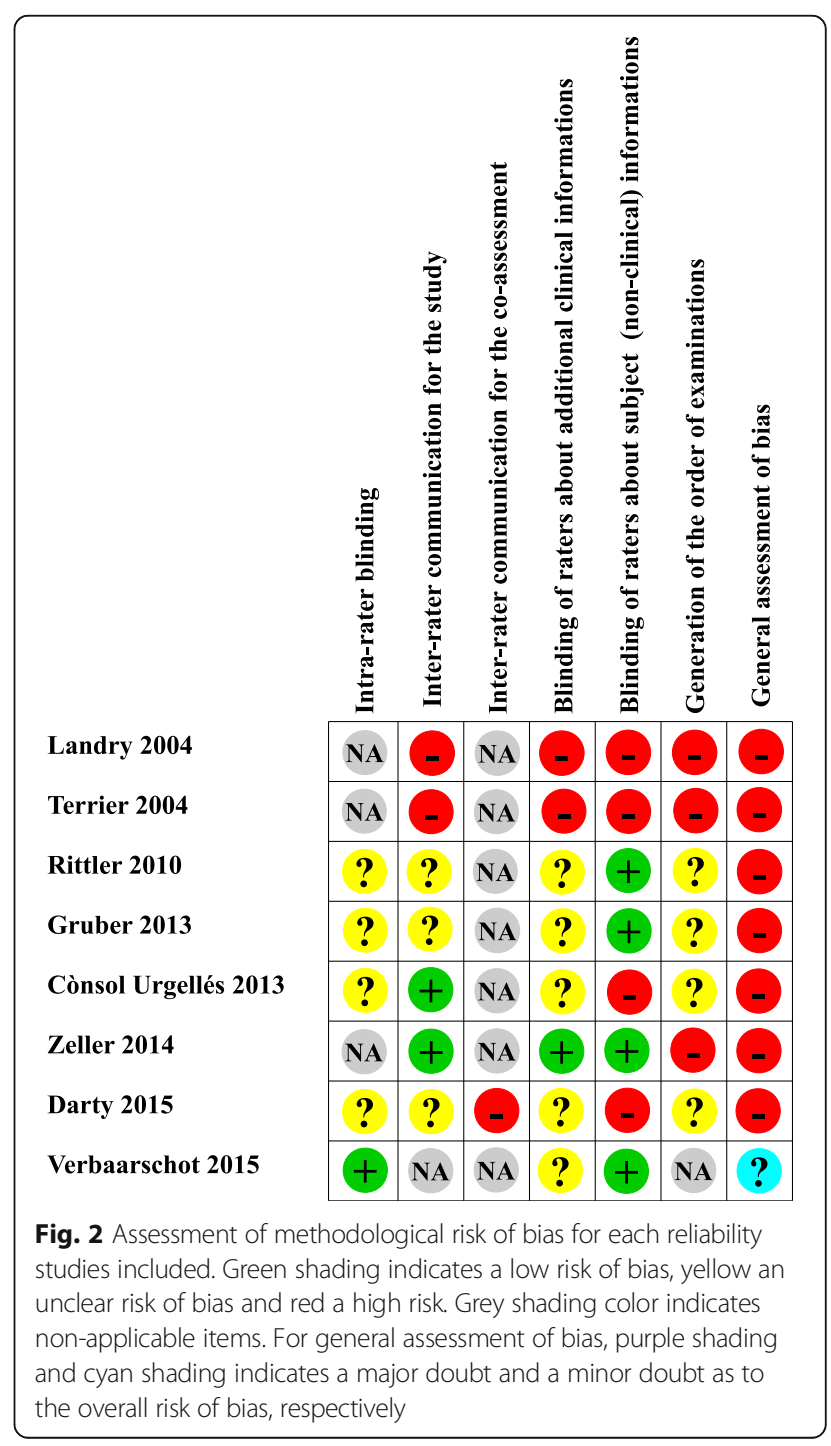




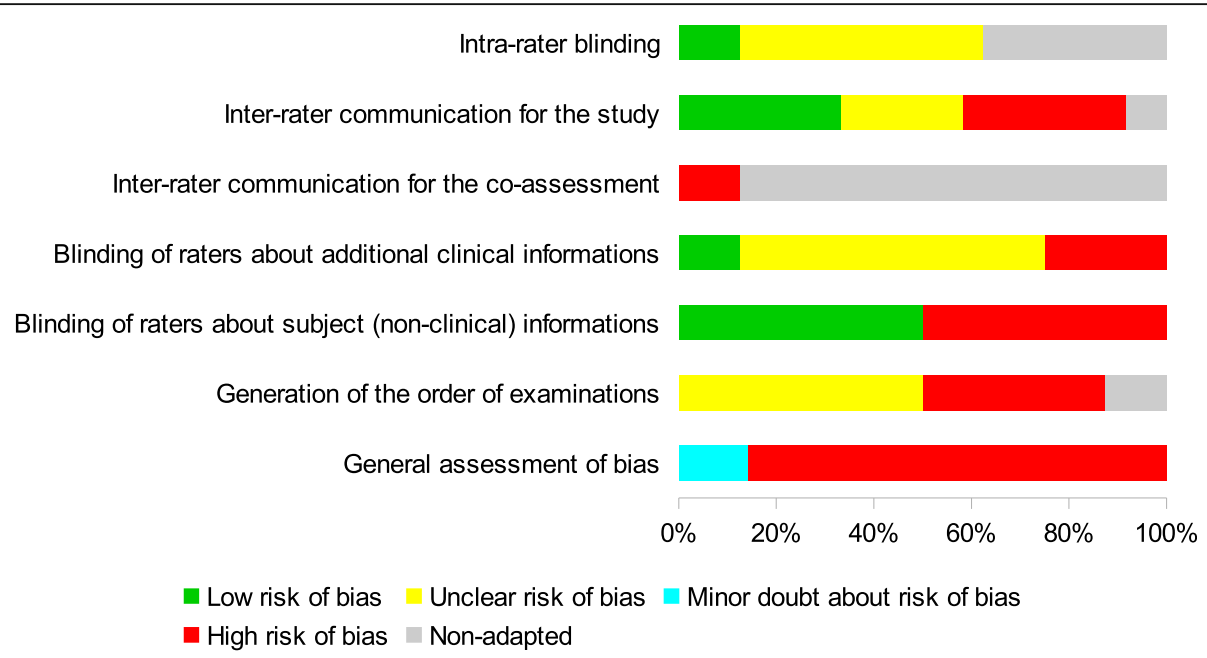

Fig. 3 Assessment of methodological risk of bias for the reliability studies taken together. Green shading indicates a low risk of bias, yellow an unclear risk of bias and red a high risk. Grey shading color indicates non-applicable items. For general assessment of bias, purple shading and cyan shading indicates a major doubt and a minor doubt as to the overall risk of bias, respectively

after examination of the full text are available in Additional file 2: Appendix 2 with their main reason for exclusion. Critical evaluation led to conclude that 3 studies demonstrated a high risk of bias [27-29], one had a major doubt concerning the risk of bias [26] and 2 was assessed with a minor doubt regarding the risk of bias [24, 25] (Figs 5 \& 6). Additional issues in studies with high risk of bias are found, such as the lack of a primary outcome [26-29], no Bonferroni corrections were implemented to control for inflated alpha values [25-29], the absence of interpretation of the clinical relevance of the results, no comparison between treatments, and subjective assessment with an unclear blinding procedure [25-29].

\section{Discussion}

The aim of this review has been to identify and critically appraise the scientific studies regarding the reliability of the diagnostic techniques and the clinical efficacy of therapeutic techniques used in visceral osteopathy.

No evidence is found for the reliability of diagnostic techniques used in visceral osteopathy. Most studies present a high risk of bias and fail to show reliability for evaluated outcomes. Given that the different biases detected (especially the absence of examiner blinding and absence of randomized examination order) should lead to an artificially increased measured reliability [13], this strengthens the argument that the diagnostic techniques are really unreliable.

As regards the efficacy of visceral techniques, only studies with a low risk of bias or with minor doubts concerning the risk of bias are discussed and considered as evidence. In total, two studies are discussed below.

First, the study of Panagopoulos et al. [24], is a randomized blind controlled trial designed to evaluate the efficacy of visceral manipulation in addition to "standard physiotherapy", compared with "standard physiotherapy alone", for low back pain. The main outcome is correctly defined and clinically significant, even though selfreported pain is a subjective criterion. The results demonstrate no significant statistical difference for the main outcome (pain at 6 weeks). Among the eight secondary outcomes, a clinically significative difference is found in favor of the experimental group in only one (pain at 52 weeks). This result could present a motivation for a new study with pain at 52 weeks as main outcome.

Second, the study carried out by Haiden et al. [25], is designed without a placebo treatment to compare the effects of visceral osteopathy in addition to standard care with very low birth weight infants. One primary outcome (time to complete meconium evacuation in days) and four secondary outcomes are proposed. Visceral osteopathy is shown not to be more effective than the case of no additional treatment in the acceleration of meconium passage and the enhancement of feeding tolerance in very low birth weight infants. Moreover, in the experimental group, durations of hospital stay and full enteral feeding were respectively 34 and 10 days longer than in the untreated group. Although it is not possible to deduce adverse effects of visceral osteopathy from this study alone, the absence of placebo treatment in the control group allows its interpretation as unfavorable evidence for the efficacy of visceral osteopathy in this specific context.

In summary, the two studies analyzed do not support the efficacy of visceral techniques in low back pain and for very low birth weight infants.

As a whole, the systematic review presented above shows that most studies addressing the reliability or the efficacy of visceral osteopathy have a high or unclear risk of bias. 


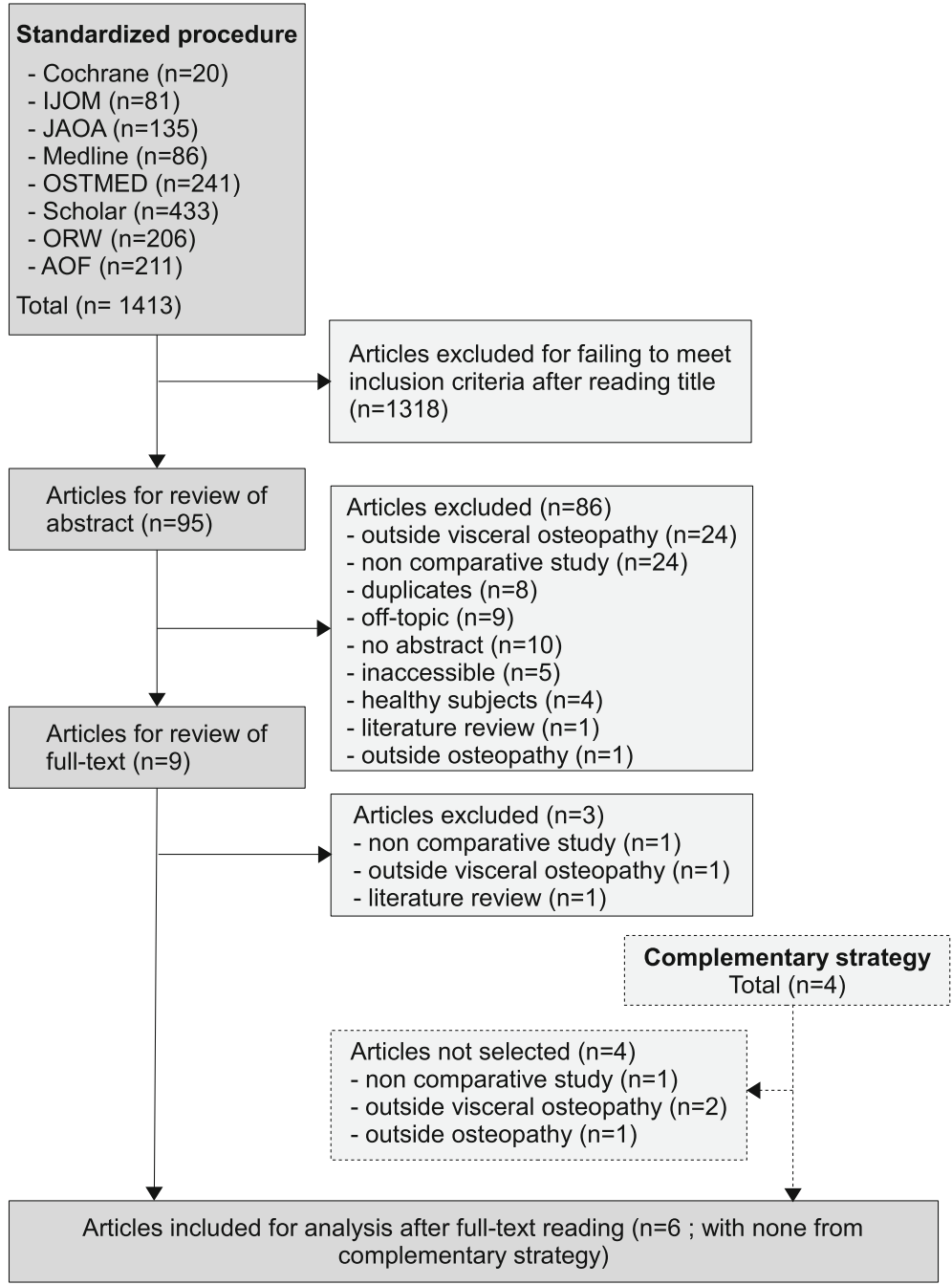

Fig. 4 Selection process for studies dealing with the clinical efficacy of techniques and therapeutic strategies used in visceral osteopathy

Therefore, there is insufficient data available to significantly inform the practice of manual therapists. These results are consistent with the last review on cranial osteopathy [10] and several reviews on osteopathic manipulative treatment (OMT) [30-33]. They highlight the requirement to enhance the standards of research methodology in osteopathy. Consequently, as undertaken for clinical research on cranial osteopathy [10], some guidance is provided to yield unbiased methodological studies and to improve the quality of study reporting in visceral osteopathy:

first, given that all reliability and two out of six efficacy studies analyzed conducted by osteopathy students, and that all these studies are rated with a high risk of bias or a major doubt about risk of bias, it is recommended to avoid (for now) studies conducted by osteopathy students in future systematic reviews, and we note room for improvement in both education and supervision of osteopathy students.
Second, in studies included in the review, most items are assessed with unclear risk of bias. This state of affairs could be improved if more methodological details were given by authors. However, it can be argued that the length of the articles is limited in many academic journals. Unfortunately, authors often opt for shortening the method section, reducing the possibility to detect potential bias. Therefore, it can be recommended either to publish separate methodology papers or to add such details as appendices or supplementary material.

Third, regarding the reliability studies, it can be recommended to future researchers in visceral osteopathy to draw inspiration from the items proposed in this systematic review and based on the QAREL. For inter-rater reliability studies, close attention must be paid to avoid raters sharing information during the entire duration of the study, consequently, studies spanning over more than 1 day are not recommended. The possibility of information-sharing between 
Table 2 Description of included studies dealing with the clinical efficacy of techniques used in visceral osteopathy

\begin{tabular}{|c|c|c|c|c|}
\hline Risk of bias & First author & $\begin{array}{l}\text { Disease \& number } \\
\text { of participants }\end{array}$ & Intervention and comparison & $\begin{array}{l}\text { Primary study } \\
\text { outcome \& result }\end{array}$ \\
\hline $\begin{array}{l}\text { Minor } \\
\text { doubt } \\
\text { about } \\
\text { risk of } \\
\text { bias }\end{array}$ & $\begin{array}{l}\text { Panagopoulos } \\
{[24]}\end{array}$ & Low back pain: 64 & $\begin{array}{l}\text { EG "standard physiotherapy + } \\
\text { visceral manipulation"/ PG } \\
\text { "standard physiotherapy + } \\
\text { placebo visceral manipulation" }\end{array}$ & $\begin{array}{l}\text { Pain intensity }(0-10 \\
\text { Numerical Pain Rating } \\
\text { Scale) at } 6 \text { wks. } \\
\frac{\text { Results show }}{\text { no SSD. }}\end{array}$ \\
\hline
\end{tabular}

Other outcomes \& results

- 8 criteria (3 outcomes after

2 wks, 2 ones after 6 wks and

3 ones after $1 \mathrm{yr})$.

1. Pain intensity $(0-10$

Numerical Pain Rating Scale).

2. Disability (Rolland-Morris

Disability Scale).

3. Function (Patient-Specific

Functional Scale).

- Results show no SSD for all criteria with the exception of pain intensity after $1 \mathrm{yr}$. [PG: 2.17; EG: 3.73].

$\begin{array}{lll}\text { Haiden [25] } & \text { Very low } & \text { EG (visceral osteopathy; } \\ & \text { birth } & \text { "protocol adapted from } \\ & \text { weight } & \text { visceral treatment of } \\ \text { infant: } 41 & \text { adults by Barral and } \\ & & \text { Finet") / untreated G }\end{array}$

The time to 4 criteria

complete meconium 1. Introduction of enteral

evacuation. Results feeding in days.

show no SSD. 2. Feeding volume on

day 14 th.

3. Time of full enteral

feeding in days.

4. Hospital stay in days.

- Results show no SSD for

all criteria with the exception

of time of full enteral feeding, in

favor of the untreated G [EG: 34;

untreated G: 26]

Tamer [26] Nonspecific low back

pain: 39
One $\mathrm{G}$ treated by OMT + physiotherapy (OMT G) / one G treated by OMT + visceral techniques (VOMT)
None

- 12 criteria (12 outcomes immediately after treatment).

1. Pain intensity (Visual

Analogic Scale).

2. Function level (Oswestry

Function Scale).

3. Physical function (SF-36

for quality of life).

4. Physical role limitation (SF-36

for quality of life).

5. Pain (SF-36 for quality of life).

6. General health (SF-36).

7. Energy (SF-36)

8. Social function (SF-36)

9. Emotional role limitation (SF-36).

10. Mental health (SF-36).

11. Total physical score (SF-36)

12. Total mental score (SF-36)

- Results show SSD for 3 criteria

in favor of the vOMT: physical function

[OMT G: 30; vOMT: 46]; energy

[OMT G: 10; vOMT: 22]; total physical score [OMT G: 10.5; vOMT: 20.6].

- 6 criteria (2 outcomes immediately after treatments and 1 wk. and 2 wks later).

1. Pain intensity (Visual Analogic Scale).

2. Functional disabiltity (Oswestry

Disability Index).

- Results show difference between pretest and post-test for pain intensity [untreated G: 0; EG: 0.72] and functional disability [untreated G: 0.15; EG: 5.0], and 2 wks later again for pain intensity [untreated G: 0.15; EG: 1.54]. Selective reporting of results.

45 criteria (21 outcomes 3 wks and 6 wks after treatments, and 3 outcomes 1 yr. later).

1. Constipation (Visual Analogic Scale).

2. Diarrhea (Visual Analogic Scale). 
Table 2 Description of included studies dealing with the clinical efficacy of techniques used in visceral osteopathy (Continued)

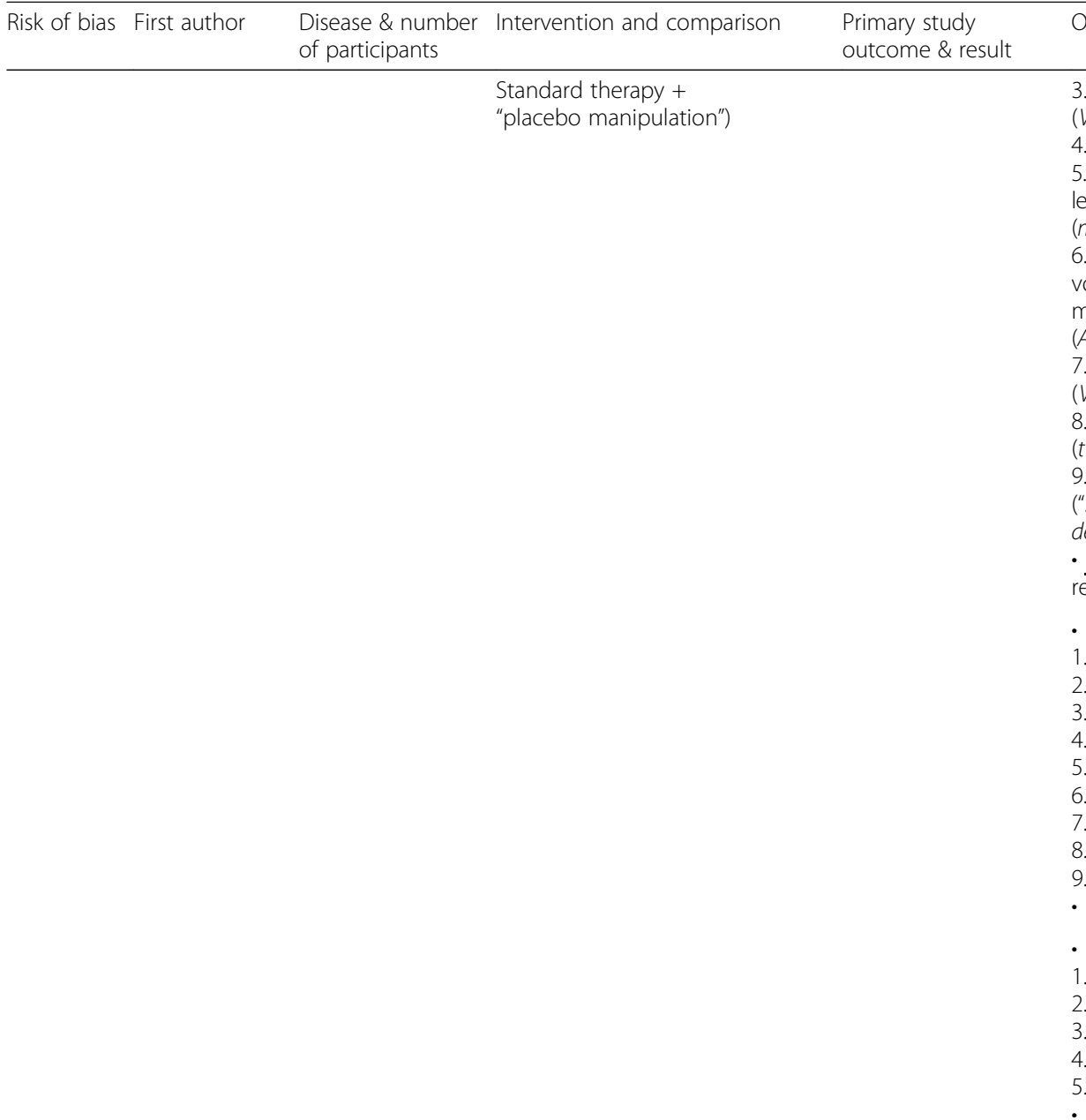

$\begin{array}{lll}\text { Rosado [29] } & \begin{array}{l}\text { Irritable } \\ \text { bowel }\end{array} & \text { EG (Osteopathic } \\ \text { syndrome: } & \text { visceral manipulation) / } & \text { "placebo treatment" }\end{array}$

Other outcomes \& results

3. Abdominal distension

(Visual Analogic Scale).

4. Abdominal pain (Visual Analogic Scale).

5. Colonic transit time: in the right \&

left colon and the recto-sigmoid

(monitoring of ingested radiopaque markers).

6. Rectal sentivity: threshold sensation

volume, constant sensation volume and

maximum tolerable volume

(Anorectal manometry).

7. Pain intensity in 9 abdominal areas

(Visual Analogic Scale).

8. Presence or absence of depression (two-question case-finding instrument).

9. Evolution of IBS phenotype

("Standardized questionnaire as

defined by the Rome III criteria").

- Results: selective reporting of

results. Number of criteria above $15^{\mathrm{a}}$.

.

7.

.

.

3.

5.

12 criteria (6 outcomes

immediately after treatments

and 1 wk. later).

1. Lumbar range of motion

(LROM) in flexion (Goniometry)

2. LROM in extension (Goniometry)

3. LROM in right side bending

(Goniometry)

4. LROM in left side bending

(Goniometry)

5. LROM in flexion

(Modified-Modified Schober Test - MMST)

6. LROM in extension (MMST)

- Results: no inter-group statistical

comparison; outcomes improve

for the two groups apart from the

LROM in extension measured by the MMST.

Legend. EG experimental group, G group, SSD significant statistic difference, PG placebo group, OMT osteopathic manual therapy, LROM Lumbar range of motion, MMST Modified-Modified Schober Test

${ }^{a}$ Considering the risk of inflated alpha value and for sake of clarity, the results of the studies that both had not chosen primary study outcomes and had used more than 15 criteria were not reported

examiners requires procedures to avoid memorization of examination results. First, only the minimum requirement of clinical information concerning subjects should be given to raters and the assessment sequences (subjects and raters) should be randomized. Moreover, blinding of examiners and subjects has to be as rigorous as possible. Halma et al. [34], in the field of cranial osteopathy, for instance, implemented a suitable method to isolate the rater from visual, auditory, tactile, and olfactory cues. It should also be noted that for studies implying simultaneous assessments by two 


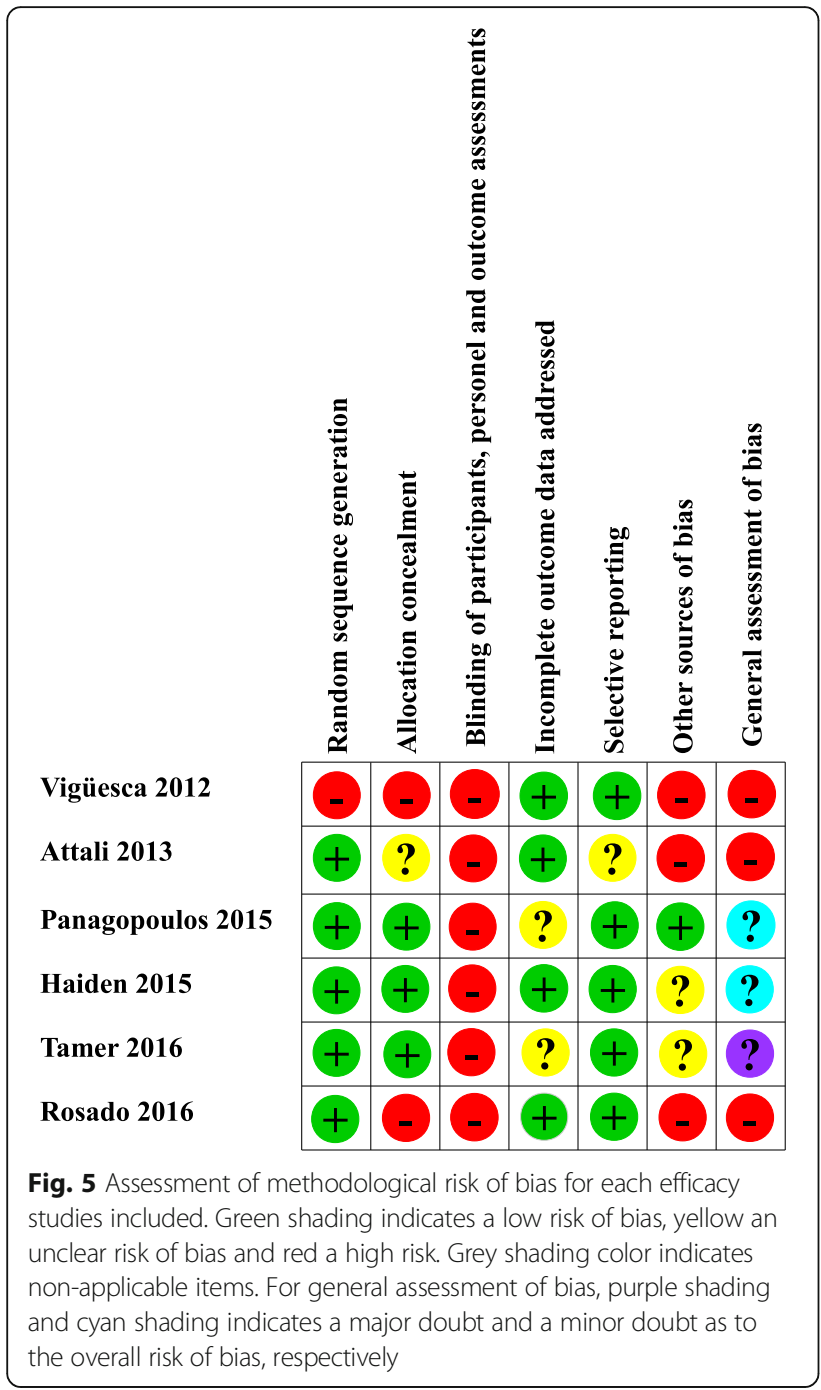

raters, the methods carried out by Rogers et al., [35], Moran \& Gibson [36], and Sommerfeld et al. [37], in cranialosteopathy studies, could be used as a guidance for this methodological aspect.

Finally, future researchers are advised to use the Cochrane risk of bias tool to design a well-built efficacy study. Moreover, the 2010 CONSORT checklist can help to implement a rigorous randomized controlled clinical trial. The exemplary methodological precautions adopted by Panagopoulos et al. [24], but also, in the field of cranial osteopathy, by Elden et al. [38], and Haller et al. [39], deserve to be underlined. However, all three studies have a bias not only because the therapeutic procedures differ (in duration, practitioner, etc.) between groups. Hence, this bias creates a risk of confusion between specific and contextual effects. To avoid this bias, future researchers should rigorously standardize the different therapeutic procedures regarding the number and duration of sessions, practitioner-patient relationship, etc. Furthermore, most studies did not assess the credibility of the placebo used. Such an assessment should be conducted in future studies in order to compensate for the insufficient blinding procedure specific to the field. Finally, when designing a study it is important to specify one main outcome, rather than making multiple comparisons. If several outcomes are chosen, a statistical correction should be planned to offset the alpha risk inflation.

\section{Conclusion}

As a whole, this systematic review shows that currently, there is no evidence for the reliability or specific efficacy of the techniques used in visceral osteopathy. These results are consistent with the last review on cranial osteopathy and highlight the requirement to enhance research methodological standards in manual therapies, particularly in osteopathy.

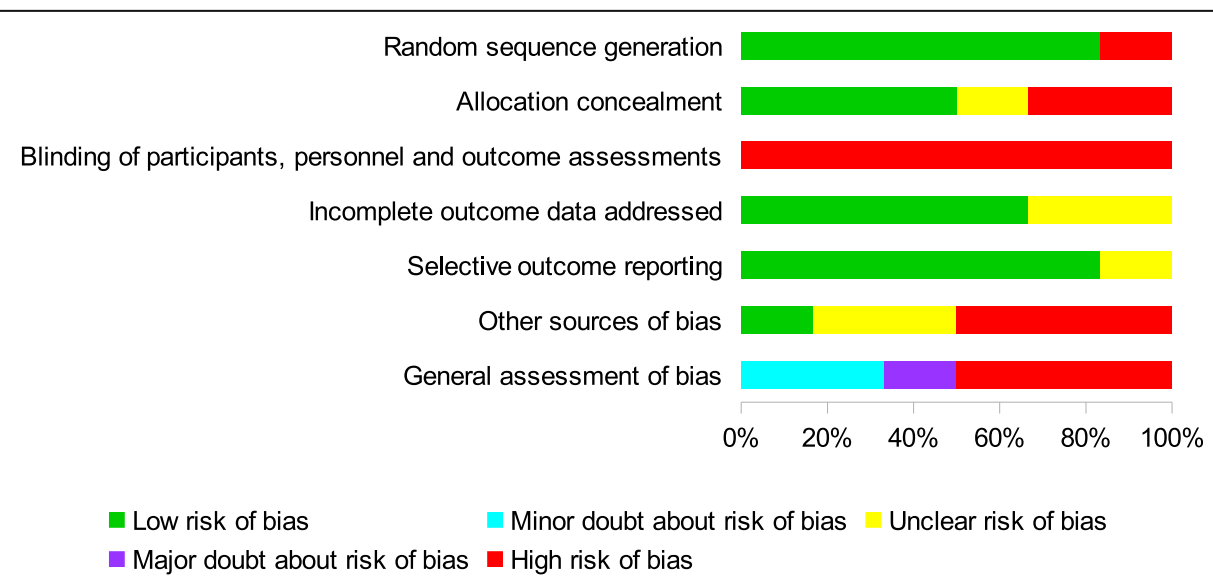

Fig. 6 Assessment of methodological risk of bias for the efficacy studies taken together. Green shading indicates a low risk of bias, yellow an unclear risk of bias and red a high risk. Grey shading color indicates non-applicable items. For general assessment of bias, purple shading and cyan shading indicates a major doubt and a minor doubt as to the overall risk of bias, respectively 


\section{Additional files}

Additional file 1: Detailed search strategy for reliability and efficacy studies. Description of data: Appendix 1 contains literature sources, search terms and equations of the systematic review. (ODT $22 \mathrm{~kb}$ )

Additional file 2: Excluded articles after full-text examination. Description of data: Appendix 2 contains articles excluded after examination of the full text with their main reason for exclusion. (ODT $18 \mathrm{~kb}$ )

\section{Acknowledgments}

We would like to thank Edward Ando and Philippe Prouvost for reviewing the English of the manuscript.

\section{Funding}

This study was supported by the French national council of physiotherapists (Conseil National de l'Ordre des Masseurs Kinésithérapeutes, CNOMK, www.ordremk.fr). The sponsor had no influence or editorial control over the content of the study.

\section{Availability of data and materials}

The supporting materials used in this review are contained within the article or supplementary files.

\section{Authors' contributions}

Conceptualization: AG ND RM NP. Formal analysis: AG ND RM NP. Funding acquisition: RM NP. Investigation: AG ND RM NP. Methodology: AG ND RM NP. Project administration: AG NP. Resources: AG ND RM NP. Supervision: NP. Visualization: AG. Writing - original draft: AG NP. Reading and approving the final manuscript: AG ND RM NP.

\section{Ethics approval and consent to participate}

Not applicable.

\section{Consent for publication}

Not applicable.

\section{Competing interests}

The authors declare that they have no competing interests.

\section{Publisher's Note}

Springer Nature remains neutral with regard to jurisdictional claims in published maps and institutional affiliations.

\section{Author details}

${ }^{1}$ CORTECS team, University of Grenoble-Alpes, Paris, France. ${ }^{2}$ ThEMAS team, TIMC-IMAG laboratory, UMR CNRS-UGA, 5525 Grenoble, France. ${ }^{3}$ School of Physiotherapy, Grenoble-Alpes University Hospital, Paris, France. ${ }^{4}$ Critical Thinking Research Federation, University of Grenoble-Alpes, FED, 4270 Paris, France.

Received: 19 September 2017 Accepted: 17 January 2018 Published online: 17 February 2018

\section{References}

1. Still AT. Autobiography of Andrew T. Still, with a history of the discovery and development of the science of osteopathy, together with an account of the founding of the American school of osteopathy [internet]. 1897 [accessed 2015 Nov 15]. 404 p. Available from: https://www.atsu.edu/ museum/subscription/pdfs/still,\%20a.t/andrewtaylorstillbio1908.pdf

2. World Health Organization. Benchmarks for Training in Osteopathy. World Health Organization; 2010.

3. Cameron M. An international study of osteopathic practice [internet] [master of health science (research)]. [Melbourne]: University of Victoria; 1999 [accessed 2016 Feb 9]. Available from: http://www.vu.edu.au/research

4. General Osteopathic Council. Snapshot survey 2001 [internet]. United Kingdom: General Osteopathic Council; 2001 [accessed 2016 Mar 4] p. 14 Available from: http://www.osteopathy.org.uk/news-and-resources/ document-library/research-and-surveys/snapshot-survey-2001-results-dec$2001 /$
5. Decree of 25 March 2007 on the osteopathic training, the accreditation commission for training institutions and derogations, 43 Article 3. Sect. 3, p. 5687.

6. Weischenck J. Traité d'ostéopathie viscérale - tome 1 (French) [treatise of visceral osteopathy - volume 1]. Paris: Maloine; 1982.

7. Barral J-P, Mercier P. Manipulations viscérales 1 (French) [visceral manipulation 1]. 2nd ed. Paris: Elsevier Masson; 2004. p. 258.

8. Larciprete G, Valli E, Meloni P, Malandrenis I, Romanini ME, Jarvis S, et al. Ultrasound detection of the "sliding viscera" sign promotes safer laparoscopy. J Minim Invasive Gynecol. 2009 Jul;16(4):445-9. https://doi.org/ 10.1016/j.jmig.2009.03.023

9. Horton RC. The anatomy, biological plausibility and efficacy of visceral mobilization in the treatment of pelvic floor dysfunction. J Pelvic Obstet Gynaecol Physiother. 2015;117:5-18.

10. Guillaud A, Darbois N, Monvoisin R, Pinsault N. Reliability of diagnosis and clinical efficacy of cranial osteopathy: a systematic review. PLoS One. 2016 Dec 9:11(12):e0167823. https://doi.org/10.1371/journal.pone.0167823.

11. Fleiss JL. The design and analysis of clinical experiments. New York: Wiley; 1999. p. 432.

12. Landis JR, Koch GG. The measurement of observer agreement for categorical data. Biometrics. 1977 Mar:33(1):159-74.

13. Lucas NP, Macaskill P, Irwig L, Bogduk N. The development of a quality appraisal tool for studies of diagnostic reliability (QAREL). J Clin Epidemiol. 2010 Aug;63(8):854-61. https://doi.org/10.1016/j.jclinepi.2009.10.002.

14. Kottner J, Audigé L, Brorson S, Donner A, Gajewski BJ, Hróbjartsson A, et al. Guidelines for reporting reliability and agreement studies (GRRAS) were proposed. J Clin Epidemiol. 2011 Jan;64(1):96-106. https://doi.org/10.1016/j. jclinepi.2010.03.002.

15. Higgins J, Green S. Cochrane Handbook for Systematic Reviews of Interventions Version 5.1.0 [updated March 2011]. Cochrane Collab [Internet]. 2011 [cited 2016 Jun 25]; Available from: http://handbook. cochrane.org/

16. Landry C, Reda S, Finet G, Williame C. Tests ostéopathiques visceraux du duodémum. Étude sur la concordance des résultats obtenus par deux étudiantes de 5e année sur des sujets asymptomatiques (French) [osteopathic visceral tests of the duodenum. Study on the reliability of the results obtained by two students in their 5th year on asymptomatic subjects] [research dissertation in osteopathy]. [Belmont-sur-Lausanne]: Swiss School for Osteopathy; 2004.

17. Terrier J, Mayer-Fally. Étude pilote sur la concordance du test de la zone du côlon ascendant dans ses paramètres d'inspiration et d'expiration par deux étudiantes stagiaires sur des patients en consultation en cabinets privés (French) [pilot study on the reliability of the tests of the ascending colon in its parameters of inspiration and expiration by two students on patients in private practice] [research dissertation in osteopathy]. [Belmont-surLausanne]: Swiss School for Osteopathy; 2004.

18. Rittler M. Intraobserver and interobserver reliability of the global listening [internet] [master thesis in osteopathy]. [Krems an der Donau]: Vienna School of Osteopathy; 2010 [cited 2016 May 3]. Available from: http://www. osteopathic-research.com/index.php?option=com_jresearch\&view= publication\&task=show\&id=14549\&lang=en

19. Gruber S, Mayer-Fally E. The test of the abdominal diaphragm tension and its reliability concerning the right and left body (Interrater-test retest study) [internet] [master thesis in osteopathy]. [Frimbergergasse]: Vienna School of Osteopathy; 2013 [cited 2016 May 3]. Available from: http://www. osteopathic-research.com/index.php?option=com_jresearch\&view= publication\&task=show\&id=15394\&lang=en

20. Cònsol Urgellés N, Nin Dalmau M. The inter and intra-examiner reliability of Soto hall test in healthy people [internet] [research dissertation in osteopathy]. [Barcelone]: Barcelona School of Osteopathy; 2013 [cited 2016 May 3]. Available from: http://www.osteopathic-research.com/index.php?option=com jresearch\&view=publication\&task=show\&id=15410\&lang=en

21. Zeller U, Grant Hay A. Intertester-reliabilitätsprüfung einer visceralen mobilitätsuntersuchung an der leberzone (Deutsch) [examination of the intertester reliability of a passive visceral mobility palpation on the hepatic area] [internet] [master thesis in osteopathy]. [Krems an der Donau]: Vienna School of Osteopathy; 2014 [cited 2016 May 4]. Available from: http://www. osteopathicresearch.com/paper_pdf/Zeller\%20Ursula.pdf

22. Darty $C$, Deleigne Justamente $R$, Crépin $A$. Identification des dysfonctionnements abdomino-pelviens dans les troubles fonctionnels gastro-intestinaux (French) [identification of abdominal-pelvic dysfunctions 
in functional gastrointestinal disorders] [research dissertation in osteopathy]. Cachan: Ostéobio School of Osteopathy; 2015.

23. Verbaarschot A. Intra-observer reliability of the visceral tension test developed by Helsmoortel et al. (2002). Reliability study. [internet] [research dissertation in osteopathy]. [Fleckeby]: Academy for Osteopathy; 2015 [cited 2016 May 3]. Available from: http://www.osteopathic-research.com/index.php?option=com_ jresearch\&view=publication\&task=show\&id=15617\&lang=en

24. Panagopoulos J, Hancock MJ, Ferreira P, Hush J, Petocz P. Does the addition of visceral manipulation alter outcomes for patients with low back pain? A randomized placebo controlled trial: does visceral manipulation alter low back pain outcomes? Eur J Pain. 2015 Aug;19(7):899-907. https://doi.org/10. 1002/ejp.614.

25. Haiden N, Pimpel B, Kreissl A, Jilma B, Berger A. Does visceral osteopathic treatment accelerate Meconium passage in very low birth weight infants?- a prospective randomized controlled trial. Hills RK, editor. PLoS One 2015 Apr 15;10(4):e0123530. DOI: https://doi.org/10.1371/journal.pone.0123530.

26. Tamer S, Öz M, Ülger Ö. The effect of visceral osteopathic manual therapy applications on pain, quality of life and function in patients with chronic nonspecific low back pain. J Back Musculoskelet Rehabil. 2016 Nov;30(3): 419-25. https://doi.org/10.3233/BMR-150424.

27. Vigüesca XJ, Soler MF. Efecte del tractament de la vàlvula ileocecal en pacients amb dolor a l'articulació sacroilíaca dreta (Spanish) [effect of treatment of ileocecal valve in patients with pain to the right sacroiliac joint] [internet] [research dissertation in osteopathy]. [Barcelone]: Barcelona School of Osteopathy; 2012 [cited 2016 Apr 22]. Available from: http://www. osteopathic-research.com/index.php?option=com_jresearch\&view= publication\&task=show\&id=15555\&lang=en

28. Attali T-V, Bouchoucha M, Benamouzig R. Treatment of refractory irritable bowel syndrome with visceral osteopathy: short-term and long-term results of a randomized trial. Visceral osteopathy \&amp; IBS J Dig Dis. 2013 Dec; 14(12):654-61. https://doi.org/10.1111/1751-2980.12098.

29. Rosado Durán M, Galante Haro H, Federici E. Effect of visceral manipulation of lumbosacral range of motion in irritable bowel syndrome. Pilot study [research dissertation in osteopathy]. Barcelone: Barcelona School of Osteopathy; 2016.

30. Steel A, Sundberg T, Reid R, Ward L, Bishop FL, Leach M, et al. Osteopathic manipulative treatment: a systematic review and critical appraisal of comparative effectiveness and health economics research. Musculoskelet Sci Pract. 2017 Feb;27:165-75. https://doi.org/10.1016/j.math.2016.10.067.

31. Posadzki P, Lee MS, Ernst E. Osteopathic manipulative treatment for pediatric conditions: a systematic review. Pediatrics. 2013 Jul 1;132(1):14052. https://doi.org/10.1542/peds.2012-3959.

32. Ruffini N, D'Alessandro G, Cardinali L, Frondaroli F, Cerritelli F. Osteopathic manipulative treatment in gynecology and obstetrics: A systematic review. 2016;26:72-8.

33. Cerritelli F, Ruffini N, Lacorte E, Vanacore N. Osteopathic manipulative treatment in neurological diseases: systematic review of the literature. J Neurol Sci. 2016 Oct 15;369:333-41. https://doi.org/10.1016/j.jns.2016.08.062.

34. Halma KD, Degenhardt BF, Snider KT, Johnson JC, Flaim MS, Bradshaw D. Intraobserver reliability of cranial strain patterns as evaluated by osteopathic physicians: a pilot study. J Am Osteopath Assoc. 2008 Sep;108(9):493-502. https://doi.org/10.7556/jaoa.2008.108.9.493.

35. Rogers JS, Witt PL, Gross MT, Hacke JD, Genova PA. Simultaneous palpation of the craniosacral rate at the head and feet: intrarater and interrater reliability and rate comparisons. Phys Ther. 1998 Nov;78(11):1175-85.

36. Moran RW, Gibbons P. Intraexaminer and interexaminer reliability for palpation of the cranial rhythmic impulse at the head and sacrum. J Manip Physiol Ther. 2001 Apr;24(3):183-90.

37. Sommerfeld $\mathrm{P}$, Kaider A, Klein P. Inter- and intraexaminer reliability in palpation of the "primary respiratory mechanism" within the "cranial concept". Man Ther. 2004 Feb:9(1):22-9.

38. Elden H, Östgaard H-C, Glantz A, Marciniak P, Linnér A-C, Olsén MF. Effects of craniosacral therapy as adjunct to standard treatment for pelvic girdle pain in pregnant women: a multicenter, single blind, randomized controlled trial. Acta Obstet Gynecol Scand. 2013 Jul;92(7):775-82. https://doi.org/10. 1111/aogs.12096.

39. Haller H, Lauche R, Cramer H, Rampp T, Saha FJ, Ostermann T, et al. Craniosacral therapy for the treatment of chronic neck pain: a randomized sham-controlled trial. Clin J Pain. 2016 May;32(5):441-9. https://doi.org/10. 1097/A.JP.00000000000000290.

\section{Submit your next manuscript to BioMed Central and we will help you at every step:}

- We accept pre-submission inquiries

- Our selector tool helps you to find the most relevant journal

- We provide round the clock customer support

- Convenient online submission

- Thorough peer review

- Inclusion in PubMed and all major indexing services

- Maximum visibility for your research

Submit your manuscript at www.biomedcentral.com/submit
Biomed Central 